\title{
Revista
}

\section{DIGNIFICAR A VIDA PELA ÉTICA DO CUIDADO: COMPROMISSO DO SER HUMANO}

\section{TO DIGNIFY LIFE THROUGH CARE ETHICS: HUMAN COMMITMENT}

\begin{abstract}
RESUMO
A ação extensionista Vida: questão ética e de cuidado objetiva difundir a Ética do Cuidado como fator de princípio rumo à sustentabilidade da vida digna no planeta, auxiliando no cuidado à vida de forma integral e integrada. Apoiada numa visão sistêmica, compreende o mundo e o conviver em termos de relações e integração utilizando, em seu desenvolvimento, o método dialético. Fundamentado no pensamento de Heidegger, Freire e Dussel, defende dar-se a cura por uma ética baseada em princípios universais que não podem ser negados, negligenciados, olvidados ou negociados: vida digna, liberdade e justiça. Implica em um ethos compreendido como jeito, modo, forma de ser e de (com)viver. Estimula uma atitude prática de apoiar/criar atos conducentes à autonomia do ser numa relacionalidade saudável com o meio em que vive e com o outro ser sob a perspectiva do Cuidado. Cuidar não é apenas ver e ouvir o outro, mas ajudar a promovê-lo em seu modo de ser para que tenha dignidade de vida e no (com)viver. A necessidade da (re)vitalização do Cuidado como saber e fazer e da ética como Ética do Cuidado é imperativo para a consciência sobre a humaneidade do ser humano. As ações desenvolvidas visam fortalecer a extensão como elo da universidade e comunidade procurando dinamizar o processo ensino-pesquisa-extensão e divulgar que a URI, como universidade, encontra-se comprometida com uma causa que visa dignificar a existência do ser humano pelo Cuidado assumido como ethos.
\end{abstract}

Ilíria François Wahlbrinck

Palavras-chave: Ética. Cuidado. Vida. Saúde. Humanização.

\begin{abstract}
The extensionist action Life: ethical and care issue aims to spread the Ethics of Care as a principle factor towards sustainability of a dignified life on the planet, by assisting to care for life in an integral and integrated way. Supported by a systemic view, understands the world and live together in terms of relationships and integration using, in its development, the dialectical method. Based on the thoughts of Heidegger, Freire and Dussel defends that healing happens by an ethics based on universal principles that cannot be denied, neglected, overlooked or negotiated: dignified life, freedom and justice. Involves an ethos comprehended as way of being and live together. Encourages a practical attitude of supporting / creating acts that lead to the human being autonomy in a healthy relationality with the environment he lives in and the other under the perspective of Care. To care is not only see and hear the other, but to help promoting him/her in his/her way of being so that he/she has the dignity of life and living together. The need of Care revitalization as knowing and doing and of ethics as care ethics is imperative for awareness about the human humanity. The developed actions aim to strengthen the extension as connecting link between university and community looking to boost the teaching-research-extension process and publicize that URI, as a university, is committed to a cause that aims to dignify human existence through Care assumed as ethos.
\end{abstract}

Keywords: Ethics. Care. Life. Health. Humanization. 


\section{INTRODUÇÃO}

$\mathrm{O}$

projeto de extensão "Vida: questão ética e de Cuidado", coordenado pelos professores Claudionei V. Cassol e Claudir M. Zuchi teve, por bolsista, a acadêmica de Filosofia Ilíria François Wahlbrinck e, como colaborador, o acadêmico de Filosofia e teólogo Hélio Wahlbrinck. Fundamentado especialmente em Heidegger (1889 - 1976), Freire (1921 - 1997) e Dussel (1934), propôs a ÉTICA DO CUIDADO como forma de promover a cura por um modo de ser-no-mundo. Ou seja, a partir de um modus vivendi: já-ser-em-(no mundo)-como-ser-junto-a-compara $^{1}$. Esteve apoiado numa visão sistêmica, cuja concepção "vê o mundo em termos de relações e de integração” (CAPRA, 2006, p. 260).

Buscou revitalizar e fortalecer a Ética do Cuidado ${ }^{2}$ como Filosofia e práxis de vida, além de desenvolver nas pessoas a consciência de sua responsabilidade no cuidado com a vida, tornando-as agentes multiplicadores, parceiras, na divulgação do projeto junto aos seus pares, de modo a respeitar o contexto cultural da classe que representam. Nesse sentido, objetivou restabelecer a saúde em diferentes aspectos da vida, considerando que isso implica na não mera supressão do sintoma, pois "restabelecer a saúde visa devolver o equilíbrio a um ser humano doente. Suprimir sintomas significa perder de vista o ser humano” (KENT, 1996, p. 34). O público alvo foram lideranças comunitárias, monitoras/es e agentes de saúde, agricultores/as, professores/as e demais interessados/as do município e região.

O projeto foi desenvolvido em uma região fruto, essencialmente, da colonização europeia com cultura indígena remanescente, propícia ao desenvolvimento da agricultura familiar, rica em recursos naturais (plantas medicinais, fontes hidrominerais) e, não obstante, dependente do modelo convencional de agricultura (uso de agrotóxicos em larga escala, monocultura...). Igualmente ocorre, aqui, um franco processo de perda dos valores de cuidado da vida e promoção da saúde, práticas da cultura original (costumes populares a cair em esquecimento, já substituídas, quase que

\footnotetext{
${ }^{1}$ Heidegger, em Ser e Tempo, usa a terminologia “já-ser-em-como-junto-a-para” a fim de esclarecer sua compreensão de qual seja a vocação do DASEIN (este termo não consiste em um substantivo, mas em um verbo, carregado de sentido ontológico e sua relação com a cura, o Cuidado. Em sua tradução literal significa "ser-aí”) e que nos serve de subsídio na presente reflexão. Assim, em nossa interpretação do referido autor, o ser humano, em sua autenticidade, é um já-serem (sempre lançado num mundo, em constante e permanente abertura) - como (forma, modo de ser) - junto-a (aos outros, à realidade, ao mundo em que é possibilidade, à existência) - para (um alvo, uma meta que realiza a presença e em que esta se realiza a si mesma, em sendo, a partir de sua identidade, seu fundamento, o telos para que se dirige e que assume como realização de sua autêntica existência). Isso pode ser compreendido como um conhecimento, saber ou um ethos capaz de orientar a com-vivência.

${ }^{2}$ Usamos a maiúscula para diferenciar o termo do cuidado rotineiro com que é empregado. Não nos referimos ao cuidado banal e destituído de sentido mais amplo, mas àquele compreendido como princípio ontológico, fundante e sustentador do humano em seu modo de ser-no-mundo e que originalmente, encontra seu rizoma no termo Cura (Sorge), expressando constante empenho na busca por saúde, dignidade de vida e no conviver. Sugere-se leitura de FRANÇOIS W, Ilíria. Ética do Cuidado: significação do ser-no-mundo. In: SUDBRACK, Edite Maria (org) Diversidade na Educação [recurso eletrônico] (Série Pesquisa em Ciências Humanas; v. 4). Frederico Westphalen: Ed. URI, 2011 p. 85-93
} 
totalmente, pelo modelo químico-industrial - alopático - e a cultura de subsistência sendo substituída, paulatinamente, pela agroindústria e produção integrada); isso, sem apontar o ainda crescente êxodo rural. Tais fatores provocam a perda de autonomia comunitária e pessoal com suas mais variadas implicações e consequências. Em tal contexto é mister a tomada de atitudes visando construir e fortalecer modelos de desenvolvimento sustentável, bem como a promoção da saúde.

Para a proposta do referido projeto, considera-se que a época atual encontra-se caracterizada por uma série de problemas complexos, exigentes de novas respostas. Os fenômenos observados a partir da tecnociência, que não passam de resultados (e que não são compreendidos como fenômenos), têm orientado diversas práticas e, dessa forma, a ciência e suas tecnologias (com sua visão mecanicista e reducionista) parecem ter nos conduzido a um saber que pode não contribuir com a promoção e o cuidado da vida. Na medicina, o modelo cartesiano reduz a compreensão do ser humano a uma visão mecanicista. Na família, os pilares de respeito, responsabilidade e copertença encontram-se subordinados à ausência de limites com seu consequente narcisismo. A humanidade agoniza sob o jugo de uma era que insiste em tentar estabelecer e manter um modelo dicotômico e compartimentista que sufoca o que a ela é mais essencial: sua eticidade.

Talvez precisamente na atualidade as regras hipocráticas Primum non nocere et Bonum facere (princípios considerados como sendo as primeiras regras morais existentes) precisam ser compreendidas como sendo ainda válidas e precisem ser revitalizadas para que a humanidade possa ser restabelecida e dignificada em sua essência e tornar-se humana. Talvez - até - tenha que se priorizar o Bonum facere sobre o Primun non nocere a fim de revitalizar o humano no humano ${ }^{3}$. Onde se busca e se quer dignidade de vida, há necessidade de uma ética que perpasse o antropológico e o epistemológico, um ethos que se caracterize como COMvivência ${ }^{4}$. Requer-se ética que não possa ser relativizada, mas que se mostre comprometida com uma aplicabilidade prática contextualizada que contemple a complexidade e a complementaridade.

\section{REVISÃO DA LITERATURA E FUNDAMENTOS TEÓRICOS}

Facilmente perceptível como traço característico da humanidade ao longo do tempo, o Cuidado (derivado de Cura/Cogitare-cogitatus/Sorge - cuidar) está bem presente na sua cultura (nas práticas religiosas, na medicina, no folclore e nas lendas). Ao usar os recursos da natureza (plantas, água, terra, sol) como fonte de suprimento de necessidades das mais diversas, numa relação de interação, o ser humano alcançou êxito no tratamento de suas dificuldades orgânicas e no

\footnotetext{
${ }^{3}$ Sugere-se leitura de FRANÇOIS WAHLBRINCK, Ilíria. Cuidado: significação do dasein na existência humana. In: CASSOL, Claudionei V.; ZUCHI, Claudir M. e COCCO, Ricardo (org.). Estudos Filosóficos: Interfaces da Filosofia no mundo contemporâneo. Frederico Westphalen: URI, 2011.

${ }^{4}$ Termo assim posto para destacar que conviver não é apenas viver junto, mas viver com
} 
suprimento de necessidades do dia-a-dia. Elementos e fenômenos da natureza eram usados, também, na explicação do que não lhe parecia claro e compreensível, o que é perceptível na força dos mitos. Hoje, o uso de recursos naturais no cuidado e promoção da vida nos leva, cada vez mais, a buscar esclarecimentos sobre o que pode ser encontrado a nossa volta e sua forma racional de uso. Tais recursos, não poucas vezes usados indiscriminadamente, evidenciam o risco da extinção de certas espécies vegetais e animais, o espólio e desequilíbrio do ecossistema, o enfraquecimento da saúde e o aparecimento de distúrbios funcionais dos mais diversos não só no campo biofísico, mas, também, a nível sócio-econômico e cultural.

Nessa realidade, fala-se de crise especificando-se as mais diversas e diferentes áreas, aludindo, até mesmo, a uma 'crise da ética': "ganhamos um complexo de ideias “crísicas”. [...] Dessa forma, estamos num mundo em crise” (MORIN, 2010, p.34). A pergunta que se levanta é: onde reside a crise? Pode-se, definitivamente, especificar diferentes crises? Ou há uma só crise, que se reflete no todo, que ora se encontra reduzido e fragmentado? Pode-se identificá-la como crise de sentido ético? Seria uma crise de compreensão de sentido do humano no homo? E que crise seria essa, então?

Vivemos, assim, um momento de crise, em que conceitos e valores estão a ser revistos, bem como a capacidade de valorar, num esforço por conduzir a humanidade a uma visão de cooperação e solidariedade, uma vez que "a ciência moderna é um saber que nos diz como o mundo é. Da finalidade e do sentido da vida não diz nada” (BELLINO, 1997, p. 89). Observamos um franco processo de perda dos valores de cuidado da vida e, ao invés de evoluir-se para uma sensibilidade a favor da vida, acontece um embotamento, uma verdadeira cauterização da consciência e a consequente banalização do mal. Se, por um lado, tal cauterização acontece e daí decorre a falta de perspectivas no que tange à ética do cuidar, por outro, sobram soluções associadas, não raras vezes, ao individualismo e ao consumismo, seja na forma de produtos ou de comportamentos (intra e inter humanos, onde o próprio ente e também o outro é apenas um meio e não um fim).

Não obstante, diante da crise, buscam-se soluções, o que faz com que ela seja, também, sinônimo de possibilidade. Enquanto para muitos a saída é o delírio do hibridismo (que origina a perda de raízes), alguns solitários buscam, na responsabilidade, as bases para uma nova vivência, onde a Ética do Cuidado desponta como promissora possibilidade. Dessa forma, apesar de soar catastroficamente, a crise pode, também, representar possibilidade; não só desafio, mas oportunidade e “chance única para definir um uso convivial dos instrumentos tecnológicos a serviço da preservação do planeta, do bem estar da humanidade e da cooperação entre os povos.” (ILLICH, apud BOFF, 2004, p.125). 
Diante da realidade dicotomizada, fragmentada pelo entendimento mecanicista vigente em quase todas as áreas do saber e do (com)viver, percebe-se a busca por uma ética que contemple uma redefinição de valores e de princípios bem como a racionalidade na capacidade de valorar que possa conduzir-nos a uma existência mediada pelo senso de responsabilidade e a uma revitalização da humaneidade $^{5}$ no humano. É preciso aprender o sentido de valores e aprender a capacidade de valorar valores que contribuam para uma vida digna e um digno (com)viver a fim de contemplar o Cuidado. Assim, se quisermos ser integrativos em termos de mentalidade e de vivência, de práxis, necessitamos buscar a percepção e compreensão do real a partir da totalidade. Afinal

O todo tem qualidades ou propriedades que não são encontradas nas partes, se estas estiverem isoladas umas das outras e certas qualidades ou propriedades das partes podem ser inibidas pelas restrições do todo. Marcel Maus dizia: “É preciso recompor o todo”. É preciso efetivamente recompor o todo para conhecer as partes. (MORIN, 2002, p. 37).

Nas ciências biológicas e no campo da medicina, a Organização Mundial da Saúde tem alertado que "a qualidade de saúde da humanidade tem piorado, a ponto de estarmos hoje passando por uma degeneração biológica ampla, fato este que não tem recebido a atenção das autoridades sanitárias ligadas aos governos” (MACIEL, 2001: 254). A evolução da ciência, apesar de levar ao desenvolvimento de técnicas cada vez mais sofisticadas, não consegue levar ao desenvolvimento do humano:

[...] buscam-se, na verdade, as vias do progresso, do bem estar e da salvação, sobretudo fora de nós e não já no melhoramento daquilo que nós mesmos somos, dos nossos modos de pensar e de agir. O homem moderno é capaz de transformar tudo, mas esquece de desenvolver a si mesmo. (PECCEI, apud BELLINO,1997, p. 82)

Falar de Cuidado e de uma Ética do Cuidado nos remete à reflexão sobre a essência do humano e sobre o essencial no humano como individuidade ${ }^{6}$ e como coletividade em seu respectivo meio. Estará a própria humanidade em crise? Terá a humanidade se desviado do que a caracteriza? Será possível a revitalização da humaneidade a partir da compreensão da Ética do Cuidado, de uma ética que nos impele a cuidar não do que temos, mas do que somos? Entendemos que o Cuidado de si leva à compreensão e ao cuidado do outro por nele e com ele o eu poder ser, pois “... Conhecer a si próprio é uma proposta de se autogerir, de evoluir a partir de dentro, conscientizando-se, momento por momento” (RIBEIRO, 1985, p. 28). Nessa dimensão, é importante salientar a importância de que “Cabe a cada pessoa dar os primeiros passos; e isso depende exclusivamente

\footnotetext{
${ }^{5}$ Usamos o termo assim posto para reforçar a ideia do humano no ente pertencente à espécie humana, à humanidade. É preciso distinguir o termo para evitar que seja confundido com o substantivo. Ao usá-lo, referimo-nos a um modo, jeito, forma de ser moldável somente no/pelo Cuidado e que possibilita, ao ente humano, seu pertencimento autêntico à humanidade.

${ }^{6}$ Por individuidade entendemos um eu, sujeito, consciente de sua responsabilidade frente a si e junto ao outro para que a vida se realize.
} 
dela” (MORIN, 2010, p. 65). Nesse sentido, parece-nos ser de grande importância compreender a dimensão do socrático “Conhece-te a ti mesmo” como um convite à grandiosa temática do Cuidado ${ }^{7}$.

Falar em Cuidado não significa, simplesmente, arremeter a essa ou aquela crise (crise do saber, crise da economia, crise da educação, crise da política etc.), mas à crise do ser ou do ente em sua dimensão do ser (crise do humano no homo ou da humaneidade na humanidade). Decorre, daí, que talvez estejamos frente à necessidade de um novo tipo de homo? Talvez um homo-cura? Um homo que, graças à resolução, se liberta do impessoal (ditador onipresente dos afazeres humanos) e:

Deixa de pertencer ao público no sentido de submeter-se a um processo em que cada um, numa atitude de conformismo necessário, se deixa dominar pelos usos estabelecidos, juízos e opiniões, assimilando-se nas formas gerais da existência. [...] A resolução constitui a lealdade do ser-aí a si próprio. [...] A resolução liberta o ser-aí do impessoal, dando-lhe possibilidade de ser mais autêntico em suas possibilidades. [...] É a resolução que soluciona o problema da unidade do ser-aí, e fundamenta a diferença entre o ser-aí autêntico do inautêntico. (GILES, 1983, p. 108)

Capaz de estabelecer e empenhar-se por um ethos, o ser humano “é um animal ético” (MAY, 1986, p. 150). É, portanto, capaz de uma ética que contemple a vida e o (com)viver. Tratase, portanto, de empenhar-se por uma (nem tão ${ }^{8}$ ) nova visão de pessoa e de mundo e por uma mudança na forma de pensar e de posicionar-se em si e no mundo. Um posicionar-se que autentica e revoluciona, dinamiza, constrói e transforma, tornando-se verdadeiro como forma, modo, jeito de ser: já-ser-(no-mundo)-como-ser-junto-a-para.

É justamente diante da crise, na busca por soluções, que (re)surge a perspectiva do Cuidado, tendo como base o modo de ser-no-mundo. Heidegger, filósofo do existencialismo, para conceituar um atributo ontológico do ser, denominou como dasein $^{9}$ o termo que consiste no modo em como este ser constrói a si e ao mundo, através da sua relação nele e com ele. Não se trata de ser algo no mundo, mas de ser no mundo. A perda de conexão com o todo e a falta de relacionalidade entre ele

\footnotetext{
${ }^{7}$ Sócrates (Atenas, 469 - 399 a.C) teria se inspirado na inscrição da entrada do templo de Delfos para construir sua filosofia e, em sua prática pedagógica, utilizava o método maiêutico a fim de instigar ao pensar, ao refletir. Ao interrogar os homens, "os faz tomar consciência de sua ignorância a respeito dos valores que dirigem sua vida (...). O cuidado de si não tem sentido senão na perspectiva do cuidado dos outros: é preciso cuidar de si, para poder engajar-se na vida política" (KIERKGAARD, apud HUISMAN, 1997, p. 16); por isso falamos em individuidade e, a partir dela, nos remetemos à coletividade.

${ }^{8}$ Quando usamos o termo assim colocado, queremos deixar claro acreditarmos ter já havido e continuar a haver tal forma de pensar, refletir, ver, ser, sentir, fazer e viver ainda que de formas mais ou menos isoladas e não totalmente integradas. $\mathrm{O}$ atual acirramento entre os seres humanos e o fenômeno do descuido, omissão, descaso e negligência parece-nos nem sempre ter sido tão letal na história da humanidade justamente por ter havido uma forma de pensar, de ser e de (com)viver que precisa ser rebuscada, revitalizada em sua essência e re-interpretada no atual contexto em que vivemos.

${ }^{9} \mathrm{O}$ termo não consiste em um substantivo, mas em um verbo, carregado de sentido ontológico e sua relação com a cura, o Cuidado. Traduzido literalmente, significa "ser-aí".
} 
seria a falta de Cuidado, falta da condição essencial que nos caracteriza como dasein ou que nos concerne a humaneidade como atributo maior de nossa existência. Ao assumir o Cuidado como essencial ao seu ser-no-mundo, o ser se humaniza, pois ele "é o conceito unificador da condição humana e exprime a natureza de nossa existência enquanto existimos no mundo com os outros” (GILES, 1983, p. 104).

Cuidar não só é uma questão de ética, mas de uma nova ética, que parte de uma nova ótica, onde o ser humano busca salvaguardar o planeta e "cuidar" de tudo e de todos, numa forma complexa de ser-no-mundo e não somente nele estar; isso implica em responsabilidade. A autenticidade do ser humano manifesta-se naquele ser que, consciente de sua realidade, a significa e diante dela se posiciona, assumindo um ethos. Tal ethos - modo de ser e de viver - será possível a partir de um autêntico olhar para si mesmo, na construção de uma nova visão e conduta humanas nas relações com o meio e com o/a outro/a. Não obstante, para haver tal ética é preciso também haver educação. E é aí que estaremos entendendo a Ética do Cuidado como uma questão de atitude e de moral, caminhos para a cura e o resgate da humaneidade como essência do ser humano.

Cícero (apud RIBEIRO, 1985, p. 29) supõe três elementos no humano, a saber: “1. aquilo que define o homem como homem, 2. aquilo que vincula o homem a outro homem e aos homens em geral e 3. aquilo que forma o homem como homem”. Os três elementos supõem uma construção subjetiva, numa relação complexa, fazendo-nos repensar a ética como "o mister do homem” (ARISTÓTELES, apud BELLINO, 1987, p. 21) e, nesse sentido, conceder-lhe status de essência. Talvez isso nos soe estranho, considerando-se que podemos nos encontrar como que anestesiados diante de uma visão de mundo que insiste em afirmar o biológico em detrimento do espiritual. A modernidade nos faz cair em verdadeiras pseudovisões:

No mundo moderno, com a transformação da perspectiva religiosa do homem em
perspectiva científica, verificou-se uma mudança em nossa visão: de uma visão espiritual
do ser humano como agente responsável no mundo, para uma visão biológica do homem
como organismo reagente submetido a forças biológicas e sociais. (...) Enquanto na
perspectiva religiosa o homem é agente responsável, na perspectiva científica o homem é
um organismo não responsável que não age, mas exprime as consequências dos impulsos,
ou pulsões, instintos etc. O autocontrole moral cede lugar à necessidade de controles
externos (CANABARRO, apud BELLINO, 1987, p. 12).

A questão proposta representa, por assim dizer, uma revitalização do essencial ao ser humano envolvendo o cuidar de si, do outro e do ambiente, o que nos remete ao princípio da responsabilidade. Tal princípio "reside na Sorge, na preocupação ou cuidado (...) e nos torna responsáveis pelo outro, seja ele um ser humano, um grupo social, a natureza, etc. (...) A nova ética... é a responsabilidade pelo futuro” (SANTOS, 2009, p.112). A crise faz com que percebamos a necessidade de uma mudança do paradigma antropocêntrico ainda predominante para uma visão de mundo biocêntrica, comprometida com toda a vida no universo. Nesse sentido, somos desafiados 
a uma verdadeira cultura de resistência mediante a ideia da fundação, que significa constituir: 1 . núcleos de resistência de toda cultura; 2. texturas embrionárias de novas relações sociais e uma vida diferente e; 3. ilhotas de pesquisa onde haveria esforço na elaboração dos "princípios de um pensamento não mutilado/não mutilante a fim de compreender nosso modo mundo, nosso tempo, nós mesmos” (MORIN, 2010, p. 63) e sermos, essencialmente, humanos.

A época de transição paradigmática que vivemos mostra a premência por transformação, talvez a necessidade de um novo paradigma, que seria o paradigma do "conhecimento prudente para uma vida decente”, por tratar-se de uma revolução científica que

ocorre numa sociedade ela própria revolucionada pela ciência, o paradigma a emergir dela não pode ser apenas um paradigma científico (o paradigma de um conhecimento prudente), tem que ser, também, um paradigma social (o paradigma de uma vida decente). (SOUZA SANTOS, 2009, p. 74).

Nesse sentido, a educação parece possuir papel fundamental na formulação de uma nova mentalidade que leve à transformação. A educação para o Cuidado é elemento-chave na conscientização em relação à responsabilidade social na busca do desenvolvimento sustentável do planeta. Uma responsabilidade que mova a um desenvolvimento que “deve compreender o desenvolvimento conjunto das autonomias individuais, das participações comunitárias e da consciência de pertencer à espécie humana” (MORIN, 2002, p. 17). Tal responsabilidade diz respeito a uma postura individual $e$ coletiva, consciente e que nos caracteriza precisamente como humanos, a favor de uma causa ou de outrem que implique em dignidade de vida e à qual não nos podemos eximir. É responsabilidade que transcende à razão e à ação. É um sempre ser para o outro. É a descoberta de somente poder ser à medida que se é para o outro e de afirmar-se como humanidade a partir da responsabilidade, pois "a responsabilidade é o que exclusivamente me incumbe e que, humanamente, não posso recusar” (LÉVINAS, 2007, p. 84).

Considerando-se que "a pessoa é para os outros e também nos outros, para o mundo e no mundo, antes de ser em si” (MOUNIER, apud BELLINO, 1987, p. 118), remetemo-nos à alteridade. Derivado do latim alther, o termo refere-se à condição de outro em relação ao eu. Assim, a saída, diante da crise, “é transformar o inimigo em ego-alther/alter-ego” (MORIN, 2010, p. 57). A Ética do Cuidado é, pois, uma ética da responsabilidade, onde o humano recebe significado e sentido no ser responsabilidade para consigo mesmo e para com o outro (sem esperar reciprocidade). É na responsabilidade que o ser encontra e recebe sentido e significado. Nesse sentido, amplia-se o termo heideggeriano que, então, passa a ser já-ser-no-mundo-como-junto- $a$ para remetendo-nos à dimensão da transcendência a partir da imanência. Para cuidar, não basta ver e ouvir o/a outro, mas ajudar a promovê-lo/a em seu modo de ser para que tenha dignidade de vida e no (com)viver. 


\section{OBJETIVOS}

No desenvolvimento do projeto, objetivou-se:

1. promover a Ética do Cuidado como fator de princípio rumo à sustentabilidade da vida no planeta, auxiliando a população no cuidado à vida a partir da promoção de hábitos saudáveis (pessoais e coletivos) e da educação para o Cuidado e preservação do Ambiente;

2. fomentar o espírito comunitário no Cuidado à vida uma vez que, como seres humanos, somos parte de um todo maior e por ele responsáveis;

3. revitalizar e fortalecer, junto às famílias das comunidades, o conhecimento de práticas naturais de cuidado à vida e promoção à saúde e a conscientização sobre sua eficácia, difundindo seu uso correto e

4. capacitar lideranças para que se tornem agentes multiplicadores, resgatando a cidadania em saúde pela compreensão da ética do cuidar.

\section{MATERIAL E MÉTODOS}

No desenvolvimento do projeto lançamos mão de pesquisas bibliográficas procurando atender anseios expressos pela comunidade. Nos encontros o método foi sempre dialógico com vistas ao desenvolvimento de três grandes ações:

1. ${ }^{\text {a }}$ - Conscientização (curto prazo) sobre a atual realidade de perda de autonomia na área do cuidar e a crescente dependência de sistemas de saúde e cultivo ora vigentes, com equipamentos, exames, tecnologias, produtos químicos e profissionais cada vez mais especializados x a possibilidade de recuperação da autonomia na área do cuidar via revitalização de práticas de cuidado à vida.

2. ${ }^{\text {a }}$ - Formação (médio prazo) de agentes multiplicadores que atuem como cuidadores da vida em sua comunidade/localidade (item a realizar-se em parceria com o curso de farmácia) e $3^{\mathrm{a}}$ - Instalação (longo prazo) de modelos locais de referência, que possam despontar, também, como geradores de emprego e renda na área de plantas medicinais e produção orgânica (item a realizar-se em parceria com o curso de agronegócios). 


\section{RESULTADOS}

Durante o andamento do presente projeto, deu-se continuidade às ações já encadeadas em 2009, a partir do projeto “Cuidar da vida: uma questão ética”. Foi de fundamental importância a parceria com diferentes instituições como Sindicatos de Trabalhadores Rurais de Nonoai, Rio dos Indios, Alpestre, Novo Xingu, Frederico Westphalen e Movimentos pastorais em Palmitinho, Sapiranga, Ijui, Nonoai, Frederico Westphalen, Palmeira das Missões e Irai (Pastoral da Criança, Pastoral da Saúde, Pastoral da Pessoa Idosa, Pastoral do/a Agricultor/a, Ordem Auxiliadora das Senhoras Evangélicas - mantidos pela Igreja Católica, Igreja Metodista e Igreja Evangélica de Confissão Luterana no Brasil). Atividades desenvolvidas com clubes de mães, grupos de terceira idade, círculo de pais e mestres, alunos/as e professores/as de estabelecimentos de ensino foram basilares para que o projeto atingisse os níveis de discussão, reflexão e inserção que grassa atualmente, especialmente nos municípios acima citados. Procuramos fortalecer a parceria com os cursos de Agronegócios e Farmácia tentando manter seu cunho transdisciplinar no desenvolvimento de minicursos e oficinas assumidas conjuntamente e, a partir desta edição, iniciamos uma aproximação com o curso de Educação Física. Destacamos os cursos de formação para professores/as, as oficinas de multimistura nas pastorais e o Pedágio solidário, com distribuição de mudas de plantas medicinais, juntamente com a Pastoral do Agricultor, em Palmitinho - RS.

Temos participado de eventos regionais, nacionais e internacionais o que tem contribuído para que o projeto seja divulgado e alcance níveis de reflexão cada vez mais amplos e profundos, fato que ficou comprovado no Prêmio Destaque da Área de Educação (âmbito estadual) recebido durante o VII Salão de Extensão na FEEVALE, em Novo Hamburgo, em julho de 2011.

A temática esta sendo proposta, ainda, como tema de dissertação pelo PPGEDU, pela bolsista sob orientação da doutora Luci Mary Duso Pacheco e conta, para tal, com fomento da Capes.

Todas as ações desenvolvidas pelo projeto visam fortalecer a extensão como o elo que liga a universidade à comunidade procurando dinamizar o processo ensino-pesquisa-extensão “com a troca de saberes - saber popular e o saber acadêmico, além do atendimento e demandas regionais” e divulgar a toda comunidade que a URI, como universidade, encontra-se comprometida com uma causa que visa dignificar a existência do ser humano a partir do Cuidado assumido como ethos fundante do humano no humano.

Como o projeto foi novamente aprovado para continuidade no próximo biênio, visa-se aprofundar e fortalecer as iniciativas já tomadas e daí advindas em sua ampliação num claro indicativo de que "Quando filosofia e vida se confundem, não se sabe mais se alguém se debruça 
sobre a filosofia porque ela é vida, ou se preza a vida porque ela é filosofia.” (LÉVINAS, 2009, p. 22). Sonhamos, ainda, em traçar diálogo com outros cursos da URI: nutrição, enfermagem e biologia por exemplo, pois entendemos que juntos podemos mais, podemos melhor.

\section{DISCUSSÃO DOS RESULTADOS}

A partir do que expusemos até agora e diante de uma realidade em que a vida está vulnerada e da qual, como seres humanos, somos co-participantes, compreendemos que o Cuidado se impõe como imperativo para que a vida seja dignificada. No desenvolvimento do projeto, enfatizou-se, primordialmente, a educação para o cuidado com a saúde. Isso por entendermos que, apesar dos inúmeros avanços tecnológicos nos brindarem com uma série de comodidades, também implicam uma série de riscos, quando não bem conduzidos e, não poucas vezes, nos lançam num mar de engodos e equívocos capazes de anestesiar-nos diante das reais necessidades do viver, conduzindonos a um verdadeiro e catastrófico fenômeno do descuido, claramente marcado pela falta de respeito e responsabilidade para com a vida.

Tal fenômeno se faz perceber no concreto da existência humana de forma muito contundente na área da saúde onde, em nível de Brasil, as notícias são assustadoras especialmente em duas grandes áreas: medicação e alimentação. No atual modelo de “cuidado à saúde” químico-industrial, os medicamentos são a maior fonte de intoxicação, constituindo-se na principal causa de óbitos conforme dados da Fiocruz e da Sinitox (2009). As principais causas são o excesso de consumo, a interação medicamentosa, a falta de conhecimento sobre as contraindicações e automedicação (sabe-se que dos medicamentos comercializados no Brasil, apenas 1/3 é prescrito por profissionais). O Brasil é o $4 .^{\circ}$ maior consumidor mundial de medicamentos e, conforme dados do IBGE (2009), as regiões Sul e Sudeste concentram $80 \%$ das intoxicações por remédios. Do total dos casos, 25\% acontecem com crianças menores de cinco anos (é a faixa etária mais atingida!) e, só no Rio Grande do Sul, crianças de 1- 4 anos correspondem a quase 40\% das vítimas (MACIEL, 2001, p.19).

Se os dados referentes à medicalização preocupam, não menos preocupantes são as informações acerca de agrotóxicos utilizados no cultivo e produção de alimentos, onde a irresponsabilidade beira o caos e o respeito à dignidade humana parece inexistir. Eles estão entre as três maiores letalidades por agente tóxico (Fiocruz e Sinitox, 2009). Nos venenos, belamente apelidados de "agroquímicos" (talvez para não causar suspeita?) utilizados nas lavouras - de onde provém o alimento de que nos servimos - estão presentes traços alarmantes de resíduos letais. Considerando-se que mais da metade dos alimentos da dieta básica dos brasileiros provêm da agricultura familiar, os agrotóxicos definem, verdadeiramente, um quadro de saúde ou de doença 
através da alimentação. No que tange à alimentação, vemo-nos, ainda, literalmente "bombardeados” com outras informações não menos estarrecedoras. Hábitos saudáveis foram sendo, paulatinamente, substituídos, com amplo apoio midiático. Aos poucos, instalou-se a cultura da troca do integral pelo refinado e do natural pelo artificial num ato de total insensatez.

Conforme os dados do Instituto Nacional de Câncer (2009), o câncer é, no Brasil, a principal causa de morte, por doença, na faixa etária de 5-18 anos. Pesquisadores acreditam que um dos importantes motivos da elevada incidência de câncer na atualidade é o aumento da contaminação por metais tóxicos. Não obstante, considerando-se que grande parte das doenças modernas tem por base causas nutricionais e que "a alimentação industrializada é responsável por 85\% das doenças modernas” (BONTEMPO, 2004, p.49), o olhar volta-se também para outro fator, pois os alimentos refinados tornam-se a principal causa de novas doenças, sendo a industrialização alimentar a responsável pela atual decadência biológica e pelo aumento da incidência de doenças degenerativas. Soma-se, a isso, o fato de que, aliada ao sedentarismo - considerado o mal do século - a alimentação industrializada conduz à obesidade, considerada a marca oficial da atual civilização. Estudos apontam que se nossa alimentação sofresse uma redução em $50 \%$ dos produtos industrializados, especialmente no tocante ao açúcar, sal e farinha refinados, teríamos uma redução no consumo mundial de remédios de 19\% nos próximos 2 anos e de $42 \%$ nos próximos 10 anos (BONTEMPO, 2003, p. 49).

Enquanto o Cuidado vai sendo, lenta e sutilmente, olvidado e conduzido ao ostracismo pelo tecnicismo e seus aliados, algumas vozes se levantam procurando revitalizá-lo como ethos do humano, essência da humaneidade, possibilitador de vida digna ${ }^{10}$. Compreendendo-se o Cuidado como essência do humano, afirma-se que o ser humano, em sua legitimidade, é um ser de Cuidado. Sua essência encontra-se no Cuidado, sendo sua característica singular colocar cuidado em tudo o que projeta e faz, o que o torna um fenômeno ontológico-existencial básico, fenômeno que é a base possibilitadora da existência humana enquanto humana.

Talvez no que tange ao cuidado com a saúde, tenhamos que aprender, de novo, com o pensamento de Hipócrates (460-377AC, considerado o pai da medicina), cujo modelo médico estava baseado em três pilares, a saber, 1) "Que o teu alimento seja o teu remédio e que o teu remédio seja o teu alimento!” ; 2) “Andar é o melhor remédio para o ser humano!” e 3) “Todo excesso se opõe à Natureza!” (HIPÓCRATES, 2003, p. 28) e de Hahnemann (1755 - 1843, considerado o pai da homeopatia), que defendia: "Há uma só doença: pensar errado e desejar o falso!”

\footnotetext{
${ }^{10}$ Sugere-se a leitura de WAHLBRINCK, Hélio. Ética, Artifício e Natureza. In: CASSOL, Claudionei V., ZUCHI, Claudir M. e COCCO, Ricardo (org.). Estudos Filosóficos: Interfaces da Filosofia no mundo contemporâneo. Frederico Westphalen: URI, 2011.
} 
(KENT, 1996, p. 169). A sabedoria contida nos ensinamentos desses dois grandes pensadores nos deve servir de inspiração, se quisermos revitalizar o Cuidado como sentido e significação de nossa humaneidade no tocante à educação para a saúde, considerando-se que “o espírito se humaniza e o corpo se vivifica quando são moldados pelo cuidado” (BOFF, 9999, p. 190).

A vida e a morte são colocadas como possibilidade já no Antigo Testamento, no texto de Dt 30 e definem-se diante de opções que temos a fazer, a cada dia, por maiores que possam parecer e por menores que elas sejam. Assim, saúde ou doença dependem das escolhas que fazemos: o que comer e como comer; o que ler, ouvir, falar; com quem e como se relacionar; onde e como ir a algum lugar; o que e como consumir... A vida é feita de opções a cada novo passo e, na atualidade, “o estado da mente e do corpo humano é de suscetibilidade à doença, por desejar o mal, por pensar o falso e por tornar a vida uma herança ininterrupta de coisas falsas” (KENT, 1996, p. 169). A fim de optar bem, é preciso pensar bem, o que pode equivaler a dizer "pensar certo”. Urge compreendermos que "Pensar certo demanda profundidade e não superficialidade na compreensão e na interpretação dos fatos. Pensar certo é fazer certo” (FREIRE, 1980, 33) e desenvolvermos uma forma de bem pensar, que se traduza como Cuidado. Cuidar da Vida configura-se, assim, numa atitude sempre presente, um compromisso nosso de cada dia a favor da formação humana, baseada em verdadeiros princípios, que nos façam perceber que é no respeito e na responsabilidade que se torna possível restaurar a humaneidade do ser.

Trata-se, portanto, de adotar a cura, o Cuidado, como ethos, uma forma, um modo, um jeito, um como de vida fundamentado em princípios universais que não podem ser negados, negociados, restringidos, alienados ou negligenciados. Cuidar não pode ser reduzido a um ato, pois é ethos: Ética do Cuidado. Em sua radicalidade, para cuidar não basta olhar o/a outra e enxergá-lo/a, ouvir o/a outro/a e escutá-lo/a. É preciso ajudar a promovê-lo em seu ser para que tenha dignidade em seu (com)viver. É preciso, também, cuidar de si para cuidar do/a outro/a.

Percebemos, então, a necessidade de mudança que leve em consideração as atuais características da sociedade contemporânea e privilegie uma visão integral e integrativa de mundo e de pessoa, com uma postura ética, responsável e solidária: cuidadora, curadora. Percebemos a necessidade da (re)vitalização da ética como Ética do Cuidado, da responsabilidade, que em nós resgate a humanidade, pois "a humanidade verdadeira encontra-se na Ética, a Ética é a verdadeira vida e a verdadeira vida é a responsabilidade pela vida do humano” (PIVATTO, apud FABIAN, 2007, p. 200). Assim, "para onde se dirige "o cuidado", senão no sentido de reconduzir o homem novamente para sua essência? Que outra coisa significa isto, a não ser que o homem (homo) se torne humano (humanus)?” (HEIDEGGER, 2005, p. 17). 


\section{CONCLUSÃO}

Temos procurado mostrar, com as ações até agora realizadas, que a Ética do Cuidado implica numa atitude que desencadeie ações, não como ato isolado. Cuidado compreende o fundamento do ser humano, em sua essencialidade. O foco é estimular a comunidade em geral a que se conscientize da possibilidade de cultivar hábitos saudáveis, que despertem a consciência ao cuidado de si, despertar ao cuidado coletivo e da natureza, sendo esse o caminho para a sustentabilidade da vida no universo e a revitalização do ser em sua genuína essência, ou seja, sua humaneidade.

Compreender o Cuidado como ética e responsabilidade é ocupar-se não só de manter e conservar o que está bom, preservar o meio em que se vive ou mesmo a saúde, mas transformar criativamente a crise em possibilidade de cuidado da vida e do com-viver. Isso implica em ser cura, no e pelo Cuidado assumido como ethos, pois “por sua essência, o ser-no-mundo é cura” (HEIDEGGER, 2008, p. 260). O Cuidado, assim, não é uma nova técnica, mas uma revolução humanista, de cunho ontológico, na superação dialética do tecnicismo. Não se trata de simplesmente substituir o artificial pelo natural, o refinado pelo integral, não só preservar o que está bom, mas promover a saúde em sua mais ampla compreensão, em diversas esferas da existência e, assim, prevenir e superar a doença do comodismo, do imediatismo, do individualismo, do consumismo, do hedonismo, do materialismo, do relativismo e seus tantos hibridismos. Trata-se de empenhar-se e difundir uma atitude prática de apoiar e criar atos que conduzam à autonomia do ser numa relacionalidade saudável consigo mesmo, com o meio em que se vive e com o outro ser. Precisamente por isso é que falamos que o Cuidado não é ato isolado, mas uma questão de atitude ethos - caminho para a cura e o resgate da essência humana, a própria essência do ser. "Nossa tarefa é, portanto, reforçar a consciência de nós mesmos, encontrar forças integradoras que nos permitam resistir, apesar da confusão que nos rodeia” (MAY, 1986, p. 38).

Falar em Ética do Cuidado, é refletir e abordar a ética como areté ${ }^{11}$ : empenhar-se por colocar os valores humanos acima dos valores comerciais, engajar-se na defesa de uma ética baseada em princípios universais (vida, liberdade, justiça). Ser para o outro, ser com o outro, ser junto-a o outro, ser pelo outro: responsabilidade vivida e sentida na alteridade. Alteridade: o outro com quem se é, junto-a quem se é, para quem se é, pelo quem se é e que torna possível a autenticidade do ser humano.

Nosso estudo quer ser um convite, um desafio à reflexão, ao pensar, ao com-versar para transformar, para humanizar... Um convite a uma necessária mudança que leve em consideração as

\footnotetext{
${ }^{11}$ Para Sócrates, alma é sede de uma areté (virtude) que orienta toda a vida humana.
} 
atuais características da sociedade contemporânea e privilegie uma visão complexa, integral e integrativa de mundo e de pessoa, com uma postura ética, responsável e solidária: cuidadora. Nossa reflexão quer ser uma conclamação a um ethos: um modo, forma, jeito de pensar, de ser e de viver, fundamentado no Cuidado e que contemple a complexidade da existência, pela responsabilidade, no respeito e na solidariedade. Conclamação ao Cuidado compreendido e assumido como fundante do humano no humano (ou da humaneidade na humanidade) sem o que, efetivamente, não há como ser humano.

\section{REFERÊNCIAS}

BELLINO, F. Fundamentos de Bioética. São Paulo: EDUSC, 1997.

BOFF, L. Saber cuidar. Ética do Humano - compaixão pela terra. Petrópolis, RJ: Vozes, 2004.

BONTEMPO, M. Guia Médico Natural. Porto Alegre: Terra Brazil, 2004

Guia de Saúde. 2ed. Curitiba: Costa Sul, 2003

CAPRA. F. O ponto de mutação. São Paulo: Cultrix, 2006.

CASSOL, C. V. Filosofia e Ecologia: opção pela vida. Jornal O Fato. Rodeio Bonito - RS, p. 3 - 3, 2011.

- Discussão para uma Bioética Latino-Americana. Revista de Ciências Humanas (Frederico Westphalen). URI, v. Único, p. 109 - 120, 2006.

FABIAN, E. P. A crítica ao sentido e à significação intelectualista e a defesa do sentido ético do humano em Humanishe de L'Autre Homme de Lévinas. Revista de Ciências Humanas. Ano VIII, n.11. Frederico Westphalen, Departamento de Ciências Humanas da Universidade Regional Integrada, 2007.

FRANÇOIS W. I. Ética do cuidado: significação do ser-no-mundo. In: SUDBRACK, E. M. (org.)

Diversidade na Educação [recurso eletrônico] (Série Pesquisa em Ciências Humanas; v. 4). Frederico Westphalen : Ed. URI, 2011, p. 85-93.

. Cuidado: significação do dasein na existência humana. In: CASSOL, C. V.; ZUCHI, C.

M. e COCCO, R. (org.). Estudos Filosóficos: Interfaces da Filosofia no mundo contemporâneo. Frederico Westphalen: URI, 2011.

FREIRE, Paulo. Pedagogia da Autonomia. 33. ed. São Paulo: Paz e Terra, 1980.

GILES, T. R. Filosofia da Educação. São Paulo: EPU, 1983.

. História do Existencialismo e da Fenomenologia. São Paulo: EPU,1989.

HEIDEGGER, M. Ser e Tempo. 3. ed. Petrópolis: Vozes; Bragança Paulista: Editora Universitária São Francisco, 2008. 
. Carta sobre o humanismo. São Paulo: Centauro, 2005.

HIPÓCRATES. Aforismos. São Paulo: Martin Claret, 2003.

HUISMAN, D. História do existencialismo. São Paulo: EDUSC, 1997.

KENT. J. T. Filosofia Homeopática. São Paulo: Robe editorial, 1996.

LEVINAS, E. Ética e Infinito. Lisboa: Edições 70, 2007.

Entre nós: ensaios sobre a alteridade. 4 ed. Petrópolis: Vozes, 2009.

MACIEL, P. A Revolução da Medicina. Curitiba: Araucária Cultural, 2001.

MAY, R. O homem à procura de si mesmo. 12 ed. Petrópolis: Vozes, 1986.

MORIN, E. Para onde vai o mundo? Petrópolis: Vozes, 2010.

. Os sete saberes necessários à educação. 6 ed. São Paulo: Cortez, 2002.

. A cabeça bem feita. Rio de Janeiro: Bertrand, 2000.

PAVIANI, J. Filosofia da Educação. 4 ed. Petrópolis: Vozes, 2001.

RIBEIRO, J. P. Gestalt-terapia: refazendo um caminho. São Paulo: Summus, 1985.

SANTOS, B. S. A crítica da razão indolente. 7 ed. São Paulo: Cortez, 2009.

SUDBRACK, E. M. (org.) Diversidade na Educação [recurso eletrônico] (Série Pesquisa em

Ciências Humanas ; v. 4). Frederico Westphalen : Ed. URI, 2011

WAHLBRINCK, H. Ética, Artifício e Natureza. In: CASSOL, C. V.; ZUCHI, C. M. e COCCO, R. (org.). Estudos Filosóficos: Interfaces da Filosofia no mundo contemporâneo. Frederico Westphalen: URI, 2011. 